\title{
BMJ Open Assessing the impact of smoking on the health and productivity of the working- age Indonesian population using modelling
}

\author{
Regina P U Satyana, ${ }^{1,2}$ Regina E Uli, ${ }^{1,2}$ Dianna Magliano, ${ }^{1}$ Ella Zomer, ${ }^{1}$ \\ Danny Liew, ${ }^{1}$ Zanfina Ademi (1) ${ }^{1}$
}

To cite: Satyana RPU, Uli RE, Magliano D, et al. Assessing the impact of smoking on the health and productivity of the workingage Indonesian population using modelling. BMJ Open 2020;10:e041832. doi:10.1136/ bmjopen-2020-041832

- Prepublication history and additional material for this paper are available online. To view these files, please visit the journal online (http://dx.doi. org/10.1136/bmjopen-2020041832).

Received 18 June 2020 Revised 04 September 2020 Accepted 13 October 2020

Check for updates

(c) Author(s) (or their employer(s)) 2020. Re-use permitted under CC BY-NC. No commercial re-use. See rights and permissions. Published by BMJ.

${ }^{1}$ School of Public Health and Preventive Medicine, Monash University Faculty of Medicine Nursing and Health Sciences, Melbourne, Victoria, Australia

${ }^{2}$ Fakultas Kedokteran,

Universitas Indonesia, Jl.

Salemba Raya no. 6, Jakarta

Pusat, Indonesia

Correspondence to

Professor Zanfina Ademi;

zanfina.ademi@monash.edu

\section{ABSTRACT}

Objectives To estimate the impact of smoking in the working-age Indonesian population in terms of costs, years of life, quality-adjusted life years (QALYs) and productivityadjusted life years (PALYs) lost.

Methods Life table modelling of Indonesian smokers aged 15-54 years, followed up until 55 years (retirement age). Contemporary data on demographics, all-cause mortality, population attributable fractions and prevalence of smoking were derived from the Institute for Health Metrics and Evaluation. The quality of life and reduction in productivity due to smoking were derived from published sources. The analysis was repeated but with the assumption that the cohorts were non-smokers. The differences in results represented the losses incurred due to smoking. Gross domestic product (GDP) per equivalent full-time worker (US\$11 765) was used for estimation of the cost of each PALY, and an annual discount rate of 3.0\% was applied to all costs and outcomes.

Results The prevalences of smoking among Indonesian working-age men and women were $67.2 \%$ and $2.16 \%$, respectively. This study estimated that smoking caused 846123 excess deaths, 2.9 million years of life lost $(0.40 \%), 41.6$ million QALYs lost (5.9\%) and 15.6 million PALYs lost (2.3\%). The total cost of productivity loss due to smoking amounted to US\$183.7 billion among the working-age population followed up until retirement. Healthcare cost was predicted to be US\$1.8 trillion. Over a 1-year time horizon, US\$10.2 billion was lost in GDP and 117 billion was lost in healthcare costs.

Conclusion Smoking imposes significant health and economic burden in Indonesia. The findings stress the importance of developing effective tobacco control strategies at the macro and micro levels, which would benefit the country both in terms of health and wealth.

\section{INTRODUCTION}

Smoking is one of the greatest risk factors that contribute to all non-communicable diseases. In recent times, the prevalence of smoking worldwide has decreased. ${ }^{1}$ However, the prevalence of smoking in Indonesia is still high. World Bank data show that the proportion of people aged 15 years and over who smoked
Strengths and limitations of this study

- This study used a new metric measure, 'productivity adjusted life years' (PALYs), to estimate the productivity burden of smoking in Indonesia.

- The economic value of each PALY was equivalent to the annual gross domestic product per full-time worker.

- Scenario and second-order sensitivity analyses were undertaken to test the uncertainty around smoking-related inputs.

- The life table modelling followed best practice recommendations.

- Age-specific death rates and prevalence remained constant throughout the model time horizon.

cigarettes in Indonesia increased throughout the period of 2010-2016, peaking at $39.4 \%$, which accounted for almost 103 million people. ${ }^{2}$ This high prevalence was due to the fact that smoking is introduced at a younger age, mainly through advertisements and family influences.

The healthcare costs of tobacco smoking are substantial. Data from the USA and India suggest that smoking-attributed healthcare costs range from $5.3 \%$ to $5.7 \%$ of the total health expenditure. ${ }^{34}$ Smoking is also associated with reduced productivity in the working-age population, due to workdays lost to ill-health (absenteeism) and reduced efficiency at work (presenteeism). ${ }^{3}$ The resulting loss of productivity can impose an economic burden on individuals, employers and governments through reduced earnings, tax revenue and gross domestic product (GDP). In Australia, the loss incurred by smokingassociated productivity reached $\$$ A338 billion (US $\$ 240$ billion), ${ }^{5}$ while in Malaysia the loss reached RM275.3 billion (US\$69.4 billion). ${ }^{6}$ However, these estimates were based on studies undertaken in Australia and Malaysia. 
Estimates of productivity loss at a population level in Indonesia is important as it will inform the case for investment in its prevention and control at the macro and micro levels.

In the present study, we sought to estimate the impact of smoking on the working Indonesian population, both in terms of years of life, quality-adjusted life years (QALYs) and productivity-adjusted life years (PALYs) lost due to smoking.

\section{METHOD}

\section{Life table modelling}

The present study used life table modelling ${ }^{7}$ with yearly cycles to estimate the health and productivity burden caused by smoking in Indonesia. Years of life, QALYs and PALYs lived were estimated for the cohort of Indonesian smokers of working age (15-54 years) followed up until 55 years of age, while passive smokers were not considered in these estimates due to paucity of data.

To estimate cumulative years of life, QALYs and PALYs lost due to smoking, the life table of Indonesian smokers of working age was first constructed, and then repeated but by assuming that the individuals were hypothetically not smokers. Probabilities of death were decreased in the latter group to reflect lesser risk of dying among non-smokers compared with smokers, while utilities and Productivity Indices (PIs) were both increased to reflect greater quality of life and productivity, respectively.

The differences in the outputs of the two life tables (one each for the 'smoking cohort' and the hypothetical 'non-smoking cohort') represented the years of life, QALYs and PALYs lost to smoking. All results were presented as discounted values, with an annual discount rate of $3.0 \%$, as per the Indonesian Technology Assessment Committee. ${ }^{8}$

PALYs are of similar concept to QALYs, but instead of penalising years of life for time spent with reduced quality of life due to ill health, time spent with reduced work productivity was applied instead. ${ }^{5910}$

\section{Patient and public involvement}

This is a modelling study, therefore patients and the public were not involved.

\section{Data sources}

\section{Demographic profile and mortality}

The demographic profile of the total Indonesian population was based on the 2017 population estimates from the Institute for Health Metrics and Evaluation (IHME). ${ }^{11}$ The number of deaths (from all causes) in Indonesia in 2017, stratified by 5-year age groups and sex, were derived from the Global Burden of Disease Study by the IHME. ${ }^{12}$ All-cause death rates were derived for each age and sex stratum by dividing the number of all-cause deaths by the number of people within that stratum.

To estimate mortality rates for age in single years, mortality rates for each 5-year age group was first plotted against the midpoint age for that age group (eg, 22 years for age group 20-24 years), and then polynomial functions were applied to describe the relationships between age in single years and mortality risk.

\section{Prevalence of smoking}

Data on the prevalence of smoking in Indonesia were gathered from the Global Adult Tobacco Survey: ${ }^{13}$ Indonesia Report 2011. ${ }^{13}$ To estimate prevalence for age in single years, prevalence for each age group was first plotted against the midpoint age for that age group (eg, 20 years for age group 15-24 years), and then polynomial and linear functions were applied to describe the relationships between age in single years and prevalence (online supplemental appendices 1 and 2). The second step was to regroup age in single-year prevalence to an average 5 -year age prevalence as per table 1 . The number of people who smoked (within separate age and sex strata) was calculated by multiplying the prevalence of smokers by the total population. Please refer to online supplemental appendices 1 and 2 for more information about estimated prevalence for age in single years.

\section{Mortality among smokers and hypothetical non-smokers}

Using the population-attributable risk percentage (PAR\%) for smoking (the proportion of all deaths that is attributable to smoking) and prevalence of smoking for each age and sex stratum, it was possible to calculate mortality specifically for non-smokers according to the following equations:

$\mathrm{PAR} \%=(\mathrm{Rt}-\mathrm{Rns}) / \mathrm{Rt}$

$\rightarrow \mathrm{Rt}-\mathrm{Rns}=\mathrm{PAR} \% * \mathrm{Rt}$

$\rightarrow \mathrm{Rns}=\mathrm{Rt}-\mathrm{PAR} \% * \mathrm{Rt}$

where,

$\operatorname{PAR} \%=$ number of all deaths in a population that is attributable to smoking

Rns = risk of mortality among non-smokers

$\mathrm{Rt}=$ risk of mortality in the total population (comprising both smokers and non-smokers), derived from 2017 mortality data.

To estimate the mortality risk for smokers, the following formula was used:

$$
\begin{aligned}
& \mathrm{Rt}=\mathrm{p} * \mathrm{Rs}+(1-\mathrm{p}) * \mathrm{Rns} \\
& \rightarrow \mathrm{p} * \mathrm{Rs}=\mathrm{Rt}-(1-\mathrm{p}) * \mathrm{Rns} \\
& \rightarrow \operatorname{Rs}=(\mathrm{Rt}-(1-\mathrm{p}) * \mathrm{Rns}) / \mathrm{p} \\
& \text { where }
\end{aligned}
$$

Rs $=$ risk of mortality among smokers

$\mathrm{p}=$ prevalence of smoking.

Data for smoking-related PAR\% in Indonesia were drawn from $\mathrm{IHME}^{14}$ for the year 2017. Sex and specific estimates of PAR\% were available. To estimate PAR\% for age in single years, PAR\% values for each age group was first plotted against the midpoint age for that age group (eg, 32 years for age group 30-34 years), and then polynomial functions were applied to describe the relationships between age in single years and PAR\% values (online supplemental appendix 3). 


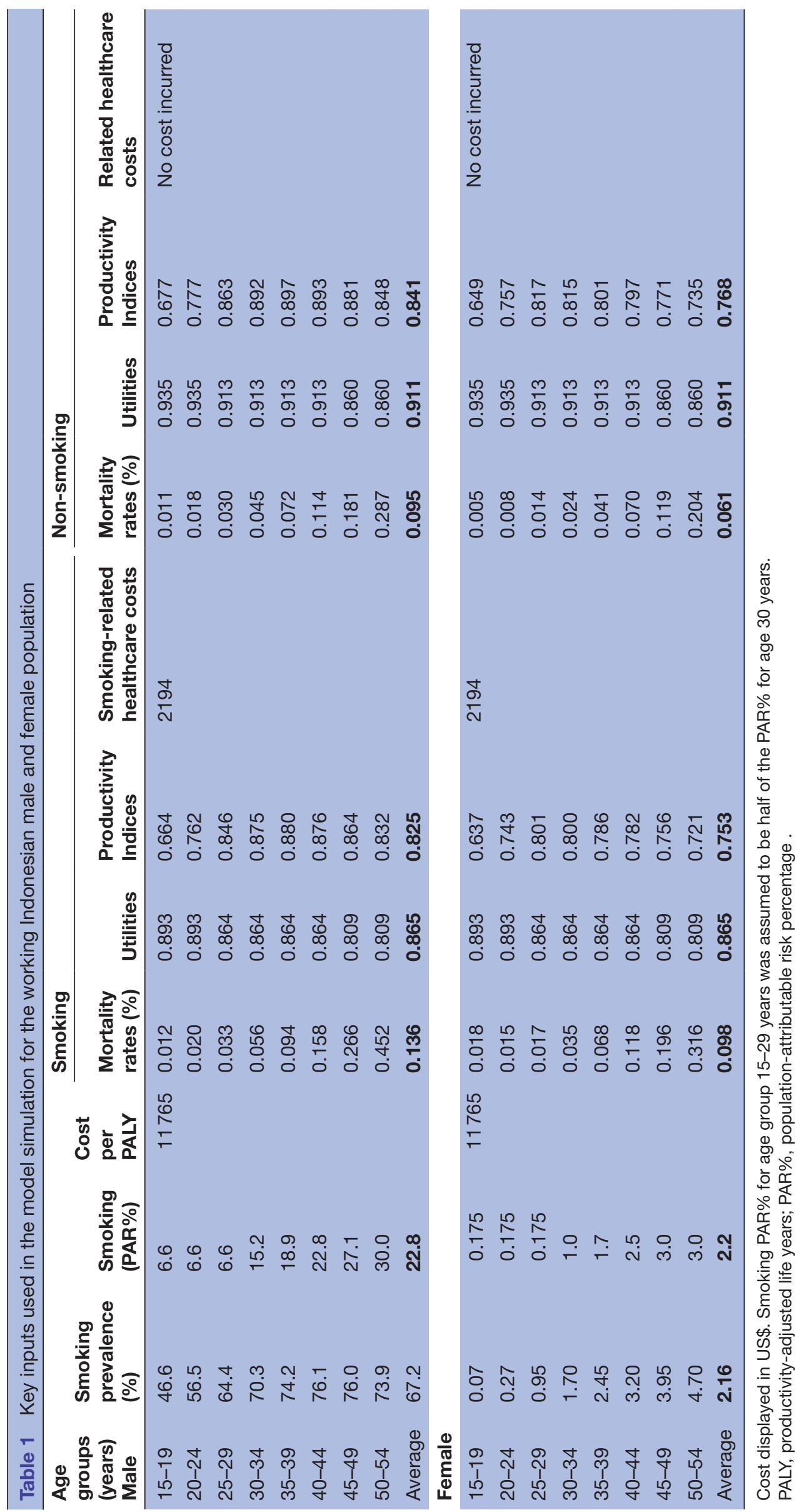




\section{Quality of life and productivity}

QALYs were derived from multiplication of years of life lived with age-specific and sex-specific utilities (table 1). Estimation of utility decrements due to smoking was based on a study by Jia and Lubetkin. ${ }^{15}$

The PI describes the proportional work productivity of a person (or a group of people), and ranges in value from 0 (non-productive) to 1.0 (fully productive). The product of PI and years lived are PALYs (in the same manner that the product of utilities and years lived are QALYs).

Smoking-attributable productivity loss (ie, productivity decrements) were estimated from a study by Bunn et $a l .{ }^{16}$ This study estimated that smokers had more unattended days of work (absenteeism) (6.7 vs 4.4 days/year) and more days with decreased productivity during work (presenteeism) (3.2 vs 1.8 days/year) compared with nonsmokers. The total working days missed in a year were quantified by combining days lost due to absenteeism and presenteeism, with smokers experiencing total missed workdays of 9.9 days/year (6.7 plus 3.2) and non-smokers experiencing total missed workdays of 6.2 days/year (4.4 plus 1.8). PIs were derived from dividing the days worked in a year (maximum working days in a year minus total missed working days) with the maximum working days in a year.

To estimate the maximum working days per year in Indonesia, the overall percentage of equivalent full-time (EFT) workers was first identified using the following formula:

Number of full-time workers + ( (part-time weekly earnings/full-time weekly earnings) *number of part-time workers)

'Labour Force Situation in Indonesia' and 'Income Statistics' data from Badan Pusat Statistik in $2018,{ }^{17}$ which estimated the number of people who worked part-time and full-time, as well as their corresponding monthly salaries in Indonesia were used to estimate EFT workers from age 15 years to 55 years. The weighted average of EFT workers across ages 15 years to 55 years in Indonesia was $83.2 \%$. Thus, the maximum working days in a year within this age range was assumed to be 199.6 days, derived from the multiplication of 240 days ( 5 working days per week times 48 working weeks per year) by $83.2 \%$.

To derive PIs for smokers and non-smokers, the number of total working days missed in a year (total days of absenteeism and presenteeism combined) was determined as a percentage of the maximum working days in a year for people aged 15 years to 55 years (199.6 days). Thus, smokers were estimated to have a PI of 0.950 ((199.69.9) /199.6), while the PI of non-smokers were estimated to be 0.969 ((199.6-6.2)/199.6) (table 1).

\section{Cost of productivity loss}

We assumed that the economic value of each PALY was equivalent to the annual GDP per full-time worker. This excluded the healthcare cost attributed to smokingrelated illness.
The cost of each PALY was obtained by dividing the total Indonesian GDP in 2019 (US\$1179 913 million or IDR16 837358510 million) ${ }^{18}$ with the estimated total Indonesian EFT workers from age 15-55 years in 2018 (100 289 529). Based on this, the cost of each PALY was estimated to be US\$11 765 (IDR168 883 998), with an assumption that all GDP was produced by Indonesian workers aged 15-55 years (table 1). Furthermore, we have forecasted temporal trends in GDP growth within a time horizon using World Bank data, applying an average annual growth of $5.17 \% .^{19}$

\section{Healthcare costs}

To estimate the healthcare costs associated with smokingrelated diseases, years of life lived (stratified by sex and age) were multiplied by smoking-related healthcare costs per person per year.

The total amount of smoking-related healthcare costs in Indonesia per person per year for smokers was estimated from a study by Kristina et al in 2018, using data from the year $2015 .{ }^{20}$ Healthcare costs per person per year were estimated by dividing the total healthcare spending devoted to smoking-related disease among the cohort (US $\$ 2177$ million) by the number of smokers (992 330) in the cohort, which equated to US $\$ 2194$ per person. It was assumed that non-smokers incurred no smokingrelated healthcare costs (table 1 ).

\section{Sensitivity analysis}

Scenario analyses were undertaken with an assumption of reduction in the prevalence of smoking by $20 \%, 30 \%$, $40 \%$ and $50 \%$. We assessed in the model the impact of applying temporal trends in annual GDP growth, removing healthcare costs for participants aged 17-29 years and 17-34 years, respectively, and removing effect of PAR\% for participants aged 17-29 years might have on the final outcomes of interest. We also performed a scenario analysis with a 1-year time horizon.

To reflect uncertainty (95\% CIs) of the input parameters in the model, a number of candidate distributions were selected. To capture the uncertainty around PAR\%s and utilities, we have used beta distributions, while for PIs and costs, we applied uniform and gamma distributions, respectively. For utilities and costs, the SE was assumed to be $5 \%$ and $15 \%$ of the means and estimate, respectively. We ran the simulation for 10000 iterations to capture uncertainty in the model using the software package @ Risk V.7.5 (Palisade, Ithaca, New York, USA). Detailed information is provided in appendices 4 and 5 .

\section{RESULTS}

The prevalence of smoking in the Indonesian working-age population was $34.7 \%$ (67\% in men and $2.16 \%$ in women), equating to 53.4 million people ( 51.9 million men and 1.5 million women) between 15 years and retirement age who smoke (table 1 ). 


\section{Deaths}

Table 2 summarises the estimated number of deaths in the smoking and the hypothetical non-smoking groups. With simulated follow-up until retirement, the smoking cohort was predicted to incur 846123 excess deaths, (830126 among men and 15998 among women). Smokingattributable deaths accounted for $12.5 \%$ (22.8\% among men and $2.2 \%$ among women) of all deaths among the Indonesian working-age population.

\section{Years of life lived}

Table 2 summarises the estimated years of life lived by the smoking cohort and the hypothetical non-smoking cohort. In total, smoking was estimated to lead to 2959283 years of life lost (95\% CI 2.5 to 3.3 million) (discounted), with 2893661 (0.4\% among male smokers) years of life lost in men and 65622 (0.4\% among female smokers) in women.

\section{Quality-adjusted life years}

Table 3 summarises the estimated QALYs lived by the smoking cohort and the hypothetical non-smoking cohort. In total, smoking was estimated to lead to 41629391 QALYs lost (95\% CI 26.1 to 100 million) (discounted), with 40750543 (5.9\% among male smokers) QALYs lost in men and 878848 (6.1\% among female smokers $)$ in women.

\section{Productivity-adjusted life years}

Table 3 summarises the estimated PALYs lived by the smoking cohort and the hypothetical non-smoking cohort. In total, smoking was estimated to lead to 15616260 PALYs lost (95\% CI (13.0 to 16.0 million) (discounted)), with 15327492 (2.3\% loss among male smokers) PALYs lost in men and 288768 (2.3\% loss among female smokers) in women. Overall, 0.29 PALYs were estimated to be lost per smoker.

\section{Cost of productivity loss}

The cost of PALYs lost due to smoking was derived by assuming a constant GDP per full-time worker of US $\$ 11$ 765. In total, smoking was associated with US\$183 726339 465 loss in GDP (95 CI 148.4 to 164.3 billion) (discounted), with US\$180 328964857 GDP lost in men and US\$3397 374608 in women (table 4). GDP lost per smoker was estimated to reach US\$3435 among the working-age population followed up until retirement (table 4).

\section{Healthcare costs}

Overall, discounted results showed that the smokingattributable healthcare costs in Indonesia were estimated to be US\$1837 669140149 (95\% CI 1.82 to 1.85 trillion). Men incurred smoking-related healthcare costs of US\$1799 385510 167, while women incurred US\$38 283 629982 among the working-age population followed-up until retirement (table 4 ).

All other undiscounted results are provided in the online supplemental appendices 6 and 7 .

\section{Scenario analyses}

A number of scenario analyses were undertaken in which the prevalence of smoking was hypothetically reduced by $20 \%, 30 \%, 40 \%$ and $50 \%$ (figure 1 and appendix 8). In total, halving of the current prevalence of smoking would return approximately 1.4 million years of life, 20.3 million QALYs, 7.6 million PALYs, US $\$ 90$ billion in GDP and save US\$899 billion in smoking-related healthcare costs.

Running the model for 1 year only, lead to 10414 years of life lost, 2573566 QALYs lost, 874136 PALYs lost, US $\$ 10.2$ billion loss in GDP and 117 billion loss in healthcare costs (table 5). Furthermore, additional scenario analyses showed that removing healthcare costs and annual GDP growth had a major impact on final outcomes of interest. For example, applying an annual GDP growth of $5.17 \%$ increased total PALYs lost by $98 \%$ (table 5 ). Of note, removing healthcare costs for ages 17-29 years and 17-34 years reduced total healthcare costs by $15.5 \%$ and $25.3 \%$, respectively.

\section{DISCUSSION}

The present study highlights the significant impact of tobacco smoking in Indonesia, the country with the highest prevalence of smoking in the world. This study focused on productivity; the estimates exclude the burden borne by people aged older than 55 years, whereby the estimated burden would be even larger if they had been included in the analysis.

\section{Smoking impact on mortality and years of life lost}

The total number of excess deaths among Indonesian smokers currently of working age was predicted to be 846 123 , with $98 \%$ of these excess deaths occurring in male smokers. The latter reflects the extraordinarily high prevalence of smoking among Indonesian men. Of all deaths occurring among the cohort, $12.5 \%$ was attributable to smoking.

The above findings are in accordance with data from around the world. A study from Australia by Owen et al, which also used life table modelling, showed that smoking caused $23.1 \%$ of all deaths occurring in the whole population. ${ }^{5}$ Furthermore, a Malaysian study by Tan et al also using the same method showed that smoking caused $45.0 \%$ excess deaths among working-age male smokers, which accounted for $23.5 \%$ of all deaths. ${ }^{6}$ Despite the same methods, the other two studies found higher percentages of smoking-attributable deaths due to longer follow-up periods (eg, 65 years in Malaysia and 70 years in Australia).

The present study predicted that 2959283 years of life ( $0.4 \%$ among smokers) would be lost by Indonesians of current working age followed up until age 55 years.

Owen et al predicted that smoking would cause approximately 3.1 millions of years of life lost (4.2\%) among Australian smokers currently aged 20-69 years if they were followed up until 70 years. ${ }^{5}$ Indonesian smokers showed an overall similar percentage of years of life lost 


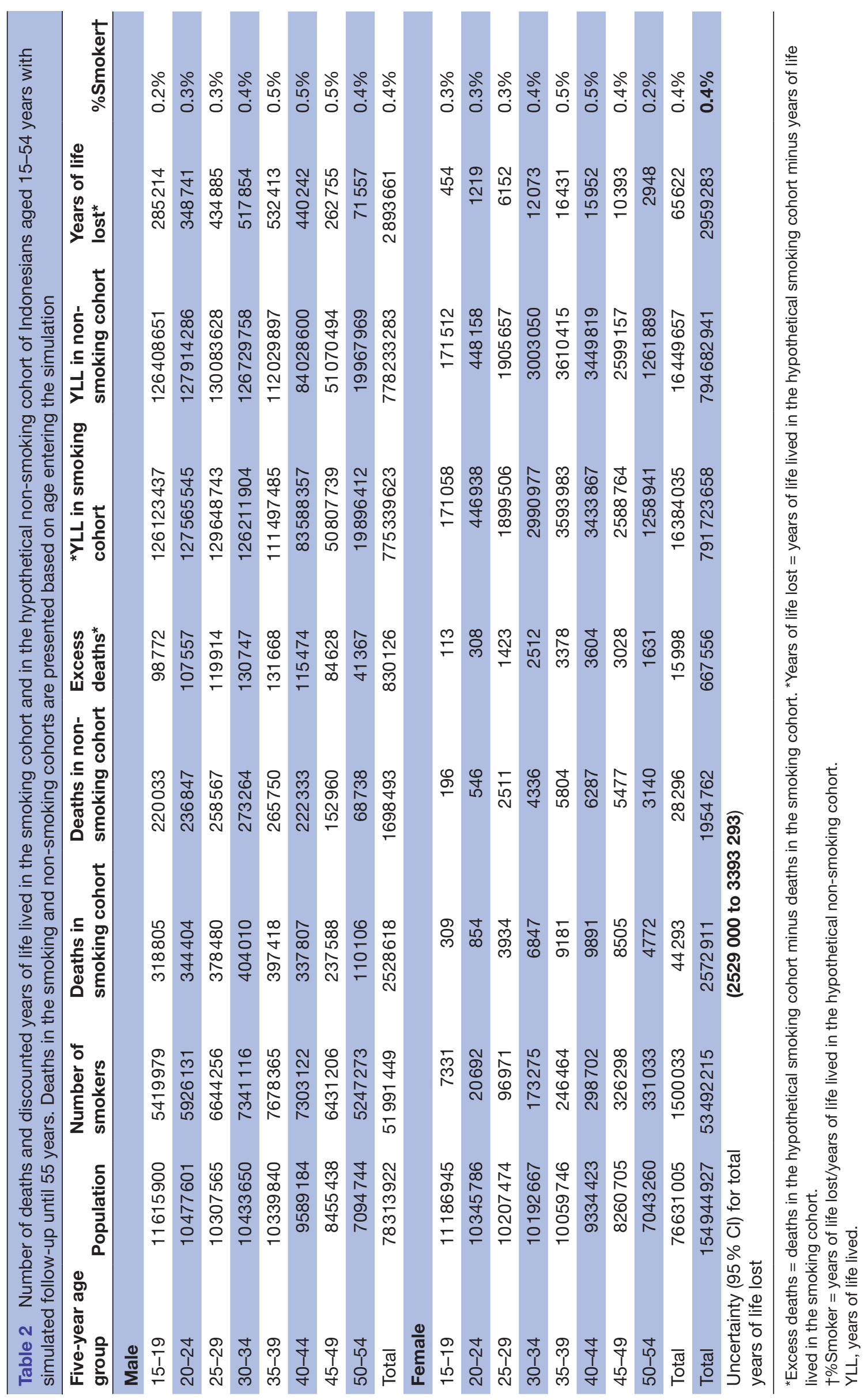




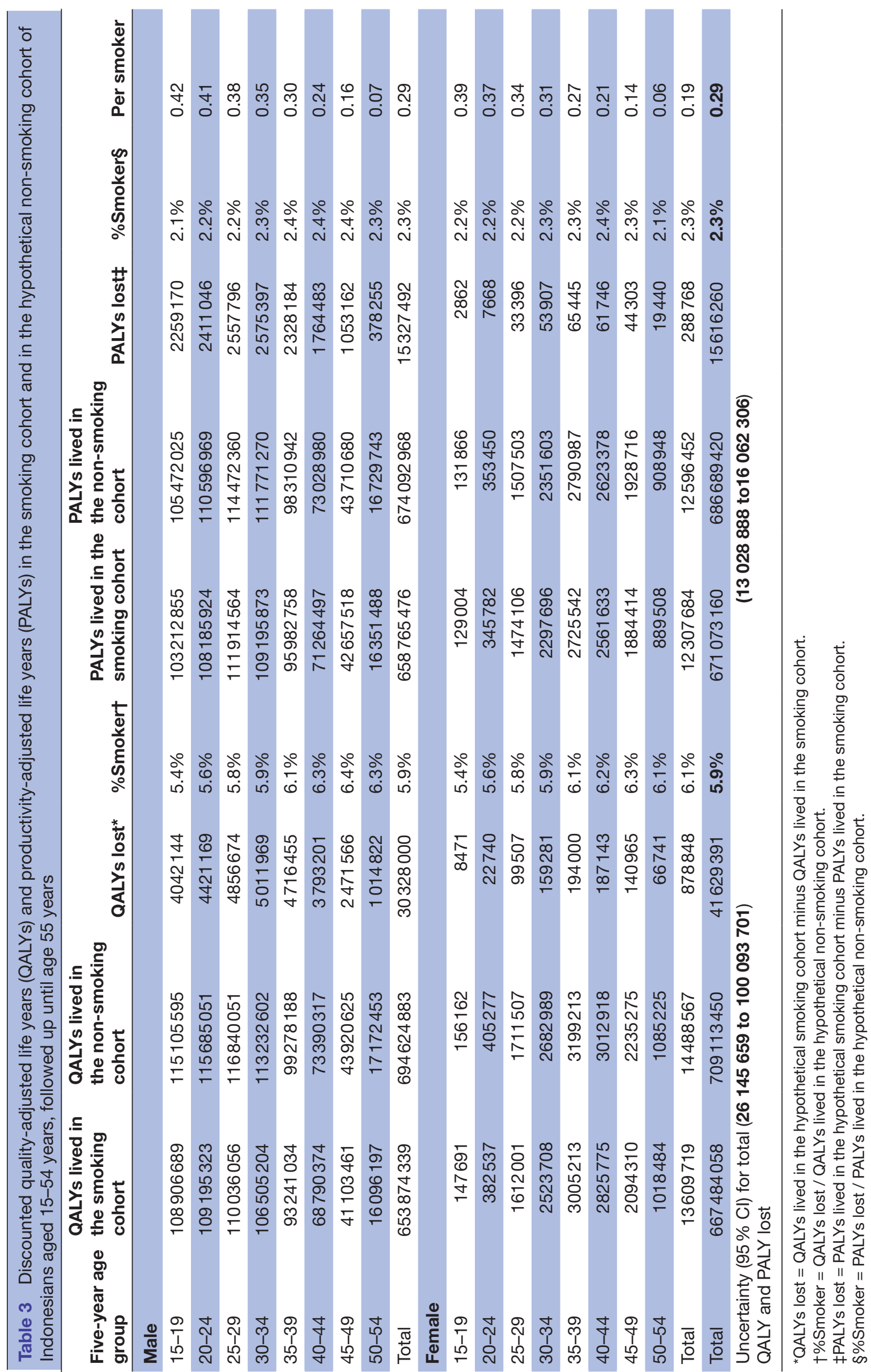


Table 4 Discounted cost of productivity and healthcare costs in the smoking cohort and in the hypothetical non-smoking cohort of Indonesians aged 15-54 years, followed up until age 55 years

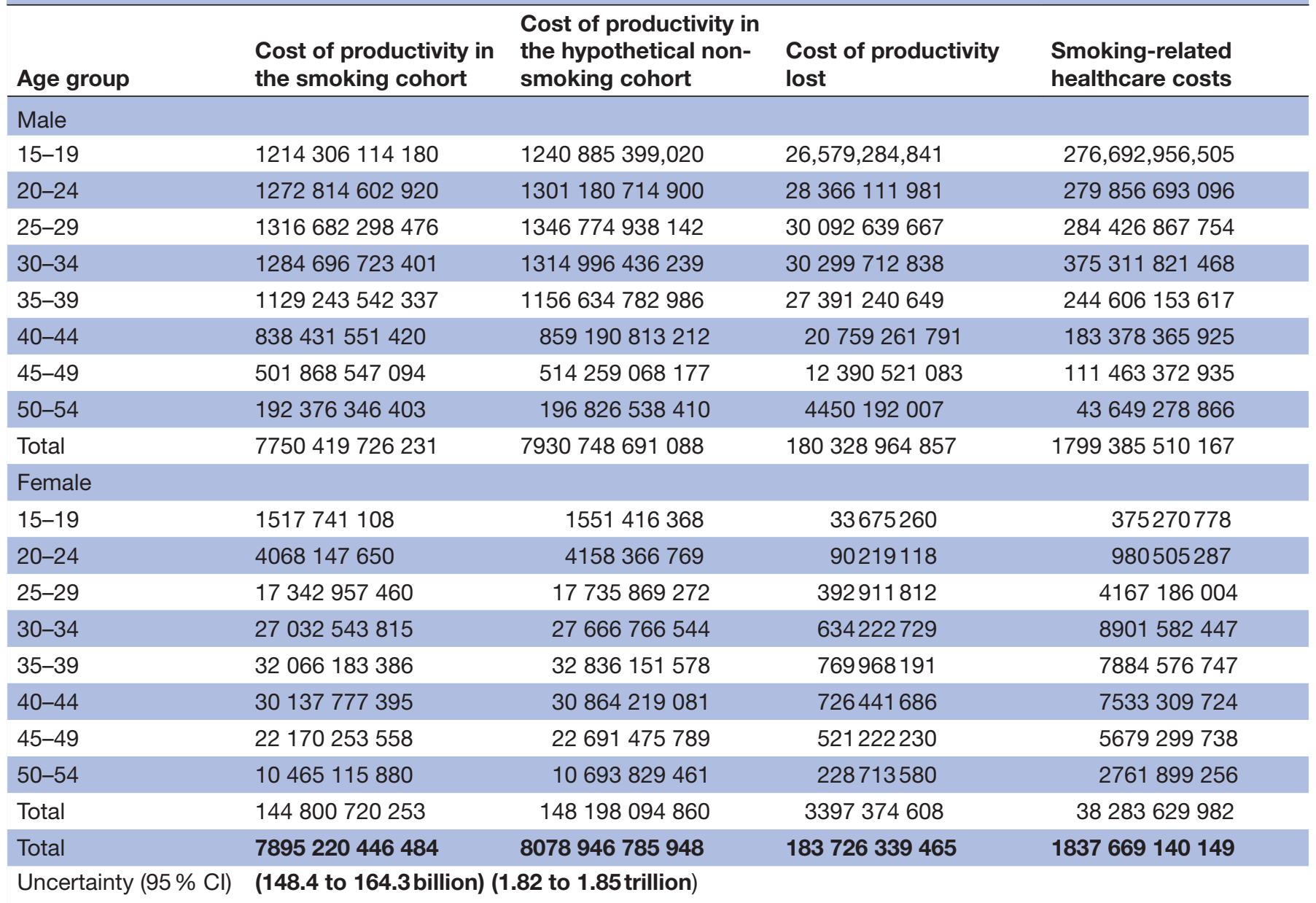

Results were derived by assuming a constant GDP per equivalent full-time (EFT) worker of US\$11 765, all costs are expressed in US\$. Nonsmoking related healthcare costs are zero.

compared with the Australian population, even though Australian years of life lost were largely due to a longer period of follow-up in the Australian study (70 years compared with 55 years), and the fact that mortality rises sharply from middle age. Furthermore, Owen $e t a \bar{l}^{\tilde{5}}$ did not apply discounting to their predictions of years of life lost. In the present study, if discounting was not applied, the loss predicted in years of life was 5.03 million.

Tan et al predicted that 2182053 years of life (2.9\% loss) would be lost by Malaysian male smokers. ${ }^{6}$ The results are not directly comparable because as mentioned, the follow-up periods were greater in the Malaysian study. Unlike Owen $e t$ al, Tan $e t$ al did apply discounting to estimated years of life lived, but this was only $3 \%$ per year, ${ }^{5}$ half of that assumed in the present study.

\section{Smoking impact on QALYs}

The present study predicted that 59.4million QALYs (6.0\% among smokers) would be lost by Indonesians of current working age followed up until age 55 years, equivalent to 0.77 QALYs lost per smoker. Again, the bulk of this burden in absolute terms occurred in male smokers, but the loss among women was greater in proportional terms (0.58 QALYs lost in women). Owen et $a \tilde{l}$ predicted that smoking would lead to a loss of 2.8 QALYs undiscounted per Australian smoker of working age, while Tan et al predicted that 1.3 QALYs would be lost per Malaysian male smoker of working age (15-65 years) ${ }^{6}$ The extent of QALYs lost per Indonesian smoker of working age was less than those predicted for working-age Australian and Malaysian men because follow-up periods for the latter two cohorts were longer.

\section{Smoking impact on productivity}

The total smoking attributable PALYs lost in Indonesian smokers, aged 15-54 years with follow-up until retirement, equated to a $2.3 \%$ loss or 0.29 PALYs lost per smoker. Similarly with smoking impact on quality of life, men bore this burden more in absolute terms, but the loss among women was similar in proportional terms.

Owen et al found that smoking caused 2.5 million PALYs lost (0.94 per smoker) among Australian working-age smokers. ${ }^{5}$ Similarly, Tan et al reported Malaysian smokers of working age lost approximately 3.0 million PALYs 


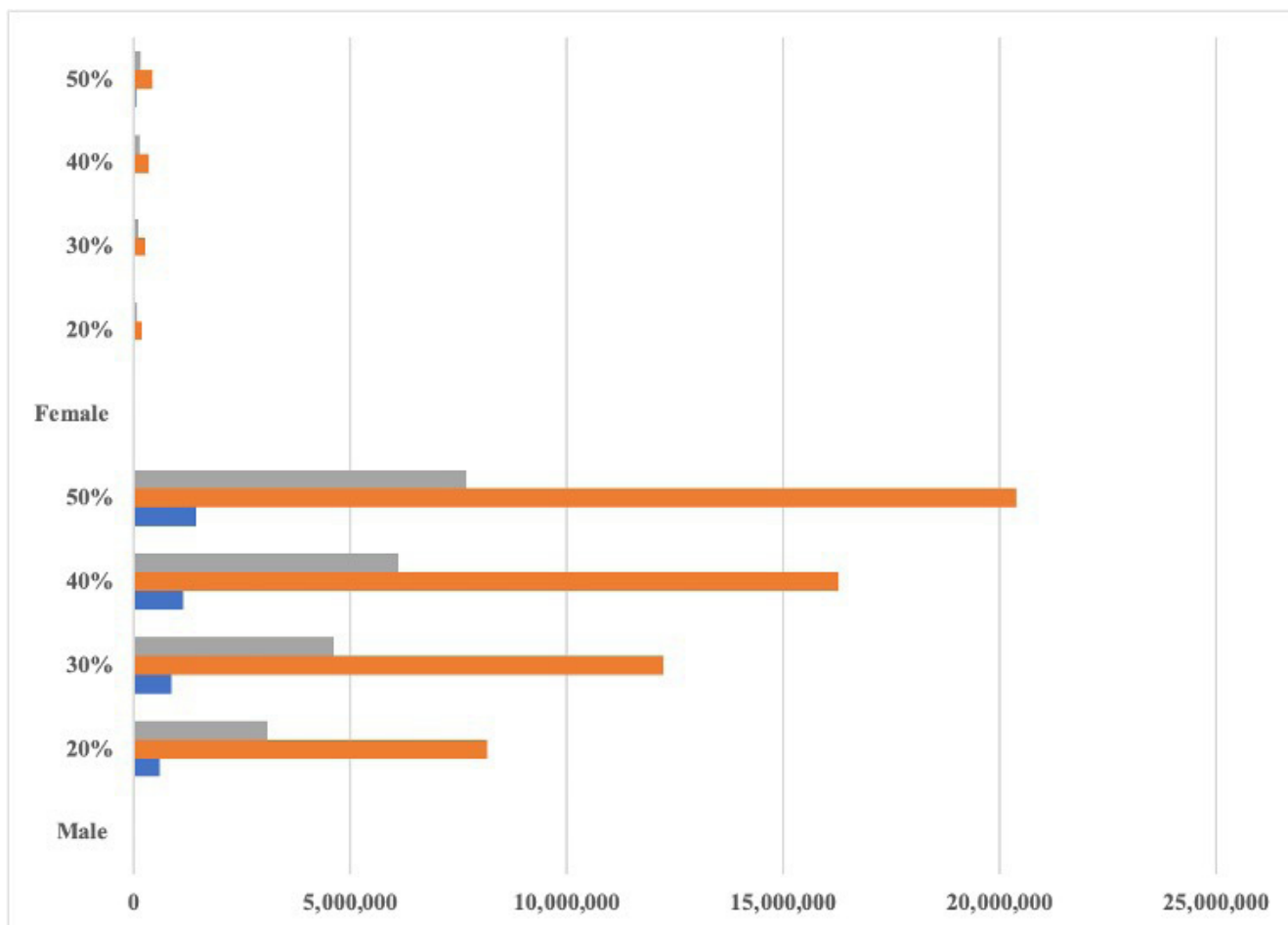

Figure 1 Gains in terms of years of life, productivity-adjusted life years (PALYs) saved, and quality-adjusted life years (QALYs) gained in which prevalence of smoking was hypothetically reduced by $20 \%, 30 \%, 40 \%$ and $50 \%$.

due to smoking, which equated to 0.70 PALYs lost per smoker. ${ }^{6}$ In absolute terms smoking attributable PALYs lost were much higher in Indonesia (ie, 15.6 million),
- PALYs gained

- QALYs gained

-Years of life gained

but in proportional terms was higher in Australia and Malaysia, due to the longer follow-up periods of the two cohorts.

\begin{tabular}{|c|c|c|c|c|c|}
\hline Description & $\begin{array}{l}\text { Total years of } \\
\text { life lost }\end{array}$ & $\begin{array}{l}\text { Total QALYs } \\
\text { lost }\end{array}$ & $\begin{array}{l}\text { Total PALYs } \\
\text { lost }\end{array}$ & Total GDP lost & $\begin{array}{l}\text { Total smoking health- } \\
\text { related costs (US\$) }\end{array}$ \\
\hline One-year time horizon & 10414 & 2573566 & 874136 & 10284268975 & 117276697420 \\
\hline Male & 9989 & 2498596 & 851417 & 10016975640 & 113986765799 \\
\hline Percentage change from base case & & & & & $-15.3 \%$ \\
\hline $\begin{array}{l}\text { Removing healthcare costs for participants } \\
\text { aged } 17-34 \text { years in the model }\end{array}$ & & & & & 1371023610646 \\
\hline Percentage change from base case & & & & & $-25.4 \%$ \\
\hline $\begin{array}{l}\text { Removing effect of PAR\% for participants } \\
\text { aged } 17-29 \text { years }\end{array}$ & 2892708 & 41572735 & 15559206 & 183055100112 & 1837815194535 \\
\hline Percentage change from base case & -0.022 & -0.001 & -0.004 & -0.004 & 0.0 \\
\hline Applying annual GDP growth of $5.17 \%$ & & & & & 364886237501 \\
\hline Percentage change from base case & & & & & $+98 \%$ \\
\hline
\end{tabular}

GDP, gross domestic product; PALY, productivity adjusted life years; PAR\%, population-attributable risk percentage; QALYs, quality adjusted life years. 
We estimated the broader economic costs of smoking, in terms of lost GDP, to be US\$3435 (0.29 PALYs) per smoker. In our other studies that have adopted the same methods, Owen et a $\tilde{l}^{\tilde{l}}$ estimated the economic impact to be US $\$ 102000$ (1.0 PALYs) per Australian smoker and Tan et $a l^{6}$ estimated the economic impact to be US $\$ 17600$ (0.75 PALYs) per male Malaysian smoker. The differences reflect major differences in GDP per capita for the three countries, as well as assumed retirement ages (Indonesia 55 years, Malaysia 65 years and Australia 70 years).

\section{Smoking-related healthcare costs}

The present study predicted that Indonesian smokers aged 15-54 years would incur total healthcare costs of US $\$ 1.83$ trillion by the time they reached age 55 years. Even when healthcare costs were removed for participants aged 15-34 years, smokers in Indonesia still incurred 1.37 trillion by the time they reached age 55 years. No previous study has estimated smoking-related healthcare costs using life table modelling; many studies have described the significant economic burden in terms of healthcare expenditure caused by smoking using varying methods. In 2012, US $\$ 422$ billion in healthcare costs was attributable to smoking globally, which was equivalent to $5.7 \%$ of the total healthcare expenditure. ${ }^{3}$ Similarly, a recent study from India assessed the economic costs of tobacco use for the year 2017-2018 for age above 35 years and found that the total economic cost attributed to tobacco was US $\$ 27.5$ billion, equivalent to $5.3 \%$ of the total health expenditure. ${ }^{4}$ Using a similar age bracket as in a recent study from India our annual estimated costs amounted to US $\$ 77.3$ billion. In Thailand, the total cost of smoking constituted $0.78 \%$ of the country's national GDP. $^{21}$

\section{Implications}

Although the present study did not evaluate the costeffectiveness of individual smoking prevention strategies, the results provide a theoretical illustration of gains from reduced smoking prevalence. Mortality due to smoking is very large in the world and any smoking-related interventions (including education, behaviour and smoking cessation therapy) are likely to reduce future mortality and related healthcare costs in Indonesia.

Several preventive measures are known to be effective, such as the use of pharmacological treatments, price-based and non-price-based policy measures, smoking cessation classes, school-based smoking prevalence programmes and workplace-based interventions. ${ }^{22} \mathrm{~A}$ meta-analysis published by the Cochrane Library in 2013 indicated that the use of pharmacological treatments for preventing tobacco intake was effective. ${ }^{23}$ However, this approach may not be the most cost-effective strategy, considering the costs range from $€ 19.69$ (US\$21.46) to $€ 624.47$ (US\$680.67) per complete course of treatment. ${ }^{24}$

Among the aforementioned preventive measures, price-based policy approaches (such as increasing tobacco taxes) and non-price-based legislation (such as prohibiting smoking in public places and workplaces, agerestriction rules and bans on advertisements) have been shown to be the most cost-effective. ${ }^{22}$ Increasing tobacco tax by $10 \%$ was proven to reduce smoking prevalence by between $4 \%$ and $8 \% .{ }^{25}{ }^{26} \mathrm{~A}$ study by Cleghorn $e t$ al in 2017 modelled the benefits of increasing tobacco taxes by $10 \%$ annually from 2011 to 2020 in New Zealand. ${ }^{27}$ The study estimated that there would be a $1.6 \%$ increase in QALYs lived among people aged 20-65 years, and savings of approximately NZ\$10.6 million (US\$6.6million) in healthcare costs. Non-price-based legislation may even be more effective, reducing smoking prevalence between $30 \%$ and $82 \%$ in the long term. ${ }^{22}$ In reality, a multifaceted approach to tobacco control and smoking prevention is required.

Although the Indonesian government has implemented a number of strategies to reduce the number of smokers (with most of the measures being legislative-based restrictions and bans), these strategies have not been well reinforced. Indonesia is the only country in Asia that has not yet signed and ratified the WHO framework convention on tobacco control, and as a consequence of this Indonesia has a very weak tobacco control policy. ${ }^{28}$

A report by the WHO in 2019 using the MPOWER measures (Monitor tobacco use and prevention policies, Protect people from tobacco use, Offer help to quit tobacco use, Warn about the dangers of tobacco, Enforce bans on tobacco advertising, promotion and sponsorship and Raise taxes on tobacco) indicated that Indonesia was still behind in terms of smoking prevention policies and programmes, health warnings and bans on cigarette advertisements. ${ }^{28}$ Furthermore, the price of cigarettes in Indonesia was found to be consistently low over many years, with a taxation of just $58.5 \%$ on retail prices, ${ }^{28}$ compared with the worldwide benchmark of $70 \% .^{29}$

Other challenges include lack of awareness concerning the negative health and economic impacts of tobacco smoking among people in Indonesia. By quantifying all the smoking-attributable losses and highlighting the benefits of reducing the prevalence of smoking (especially in terms of the broader economy), the present study will provide greater motivation to the government and policy makers for implementing tobacco control programmes.

\section{STRENGTHS AND LIMITATIONS}

The present study is the first to estimate the burden of smoking and its impact on the health and the larger economy of Indonesia. The study also used a recently derived measure called PALY, ${ }^{9}$ which permits productivity to be quantified using accessible national data as well as evaluation of various smoking prevention measures. Such information provides policy makers with better insight into the potential gains from smoking prevention measures, and hence may help inform cost-effective cessation programmes and appropriate allocation of scarce healthcare resources. 
In the past, other studies have attempted to model the burden of smoking in terms of smoking-related diseases. ${ }^{30-34}$ However, modelling the benefits of smoking cessation in this manner is limited by uncertainty arising from having to estimate its net impact mediated via the multiple smoking-related conditions. In particular, there would be significant interaction that cannot be accurately captured. Our approach minimises this uncertainty by applying the benefit of smoking cessation on the summary measures of mortality, quality of life and productivity.

The versatility of our model is a strength. Presently we demonstrate the functionality of our model using a hypothetical example of improving smoking prevalence in the Indonesian setting. However, our model can be applied in any setting as long as data exist for population mortality, PAR\% due to smoking and smoking prevalence.

There are a number of limitations of the present study. First, the analyses did not consider potential losses and gains from secondhand smoking-attributable mortality and morbidity, due to a lack of relevant data inputs from Indonesia.

Second, the period of follow-up was relatively short, with simulation only until age 55 years, the official retirement age in Indonesia. This precedes the age range within which the bulk of smoking-attributable disease manifests. The present study sought to quantify the impact of smoking among Indonesians of working age, rather than all Indonesians.

Third, despite using life table modelling, which is a commonly used tool in epidemiological and demographical studies, this approach has a well-known limitation called the life table assumption, in which age-specific death rates remain constant throughout the model time horizon. However, given that this assumption was applied to both the smoking cohort and the hypothetically non-smoking cohort, it would not have substantially affected the results, and the overall conclusion that smoking causes significant health and economic burden. Fourth, it was assumed that there was no movement of people into or out of the smoking cohort over time. That is, smokers did not quit, nor did non-smokers take up smoking within the model time horizon. While the possibility of smoking uptake after young adulthood is low, cessation does occur over time. Hence, the assumption would have led to an overestimation in the total number of smokers, and consequently the burden of smoking. The next major limitation stemmed from lack of gender-specific and age-specific healthcare costs. Therefore, the current estimates might overestimate the total healthcare costs attributed to smoking.

Finally, the present study did not consider the contribution of the local tobacco industry to Indonesia's GDP. Any changes in the prevalence of smoking would of course also affect GDP to some extent via its effect on the tobacco industry.

\section{CONCLUSION}

Smoking exerts a significant burden on both the health and economy of Indonesia. The findings of the present study stress the importance of funding effective tobacco control strategies at the macro and micro levels. We present an easy-to-apply smoking model that will help with decision making in clinical practice, public health and health policy.

\section{Twitter Zanfina Ademi @ZANFINA}

Contributors $Z A, D L$ and DM conceived the idea and contributed to the design of the work. ZA, RPUS and REU contributed to the acquisition, analysis or interpretation of data for the work. RPUS and ZA drafted the manuscript. ZA, DL, DM, RPUS and EZ critically revised the manuscript. All authors gave final approval and agree to be accountable for all aspects of the work ensuring integrity and accuracy.

Funding The authors have not declared a specific grant for this research from any funding agency in the public, commercial or not-for-profit sectors.

Competing interests None declared.

Patient consent for publication Not required.

Provenance and peer review Not commissioned; externally peer reviewed.

Data availability statement Data are available in published form and costing data are presented in the electronic supplementary files. The model is available upon reasonable request to the authors.

Supplemental material This content has been supplied by the author(s). It has not been vetted by BMJ Publishing Group Limited (BMJ) and may not have been peer-reviewed. Any opinions or recommendations discussed are solely those of the author(s) and are not endorsed by BMJ. BMJ disclaims all liability and responsibility arising from any reliance placed on the content. Where the content includes any translated material, BMJ does not warrant the accuracy and reliability of the translations (including but not limited to local regulations, clinical guidelines, terminology, drug names and drug dosages), and is not responsible for any error and/or omissions arising from translation and adaptation or otherwise.

Open access This is an open access article distributed in accordance with the Creative Commons Attribution Non Commercial (CC BY-NC 4.0) license, which permits others to distribute, remix, adapt, build upon this work non-commercially, and license their derivative works on different terms, provided the original work is properly cited, appropriate credit is given, any changes made indicated, and the use is non-commercial. See: http://creativecommons.org/licenses/by-nc/4.0/.

\section{ORCID iD}

Zanfina Ademi http://orcid.org/0000-0002-0625-3522

\section{REFERENCES}

1 GBD 2015 Tobacco Collaborators. Smoking prevalence and attributable disease burden in 195 countries and territories, 19902015: a systematic analysis from the global burden of disease study 2015. Lancet 2017;389:1885-906.

2 The World Bank Data. Smoking prevalence (Indonesia), total (ages 15+) [Internet]. Cited 2019 Mar 30. Available: https://data.worldbank. org/indicator/SH.PRV.SMOK?end=2016\&locations=ID\&start=2010\& view $=$ chart

3 Goodchild M, Nargis N, Tursan d'Espaignet E. Global economic cost of smoking-attributable diseases. Tob Control 2018;27:58-64.

4 John RM, Sinha P, Munish VG, et al. Economic costs of diseases and deaths attributable to tobacco use in India, 2017-18. Nicotine \& Tobacco Research., 2020.

5 Owen AJ, Maulida SB, Zomer E, et al. Productivity burden of smoking in Australia: a life table modelling study. Tob Control 2019;28:297-304.

6 Tan QY, Zomer E, Owen AJ, et al. Impact of tobacco use on health and work productivity in Malaysia. Tob Control 2020;29:111-7.

7 Diener-West M, Kanchanaraksa S. Life tables. Johns Hopkins Bloomberg School of Public Health, 2008.

8 Indonesian Health Technology Assessment Committee (InaHTAC). Ministry of health of the Republic of Indonesia. health technology assessment (HTa) guideline. Available: http://adphealth.org/upload/ resource/FINAL_HTA_ENG_-1.pdf [Accessed June 23, 2020].

9 Hird T, Zommer E, Owen A, et al. Productivity burden of hypertension in Australia: a life table modeling study. 2. American Heart Association, 2019.

10 Hird T, Zommer E, Owen A, et al. The impact of diabetes on productivity in China. Springer, 2019: 2.

11 Global Burden of Disease Collaborative Network. Global burden of disease study 2017 (GBD 2017) population estimates 1950-2017 [Internet], 2019. Global health data exchange (GHDx). Available: 
http://ghdx.healthdata.org/record/ihme-data/gbd-2017-populationestimates-1950-2017

12 IHME. Institute for Health Metrics and Evaluation (IHME). GDB Compare/Viz Hub [Internet], 2019. Available: https://vizhub. healthdata.org/gbd-compare/

13 Kosen S, Hardjo H, Kadarmanto, et al. Global adult tobacco survey: Indonesia report 2011. Indonesia: World Health Organisation, 2012: 162.

14 Global health data exchange. Available: http://ghdx.healthdata.org/ gbd-results-tool?params=gbd-api-2017-permalink/53e0c6ae61d9 6a91d9b079eb629fa941

$15 \mathrm{Jia} \mathrm{H}$, Lubetkin El. Trends in quality-adjusted life-years lost contributed by smoking and obesity. Am J Prev Med 2010;38:138-44.

16 Bunn WB. 3Rd, Stave GM, downs ke, Alvir JM, Dirani R. effect of smoking status on productivity loss. J Occup Environ Med 2006:48:1099-108.

17 Statistik BP. Keadaan angkatan kerja di Indonesia (labor force situation in Indonesia): Agustus/August 2018. Indonesia: Badan Pusat Statistik, 2018: 229.

18 Fund IM. World economic outlook database [Internet]. International Monetary Fund, 2017. Available: https://www.imf.org/external/pubs/ $\mathrm{ft} /$ weo/2017/02/weodata/weorept.aspx?pr.x $=21 \&$ pr.y $=9 \&$ sy $=2015 \&$ ey $=2022 \& \mathrm{scsm}=1 \& \mathrm{ssd}=1 \&$ sort $=$ country $\& d s=. \& \mathrm{br}=1 \& \mathrm{c}=536 \& \mathrm{~s}=$ NGDPD\&grp $=0 \& a=$

19 The world bank data. Available: https://data.worldbank.org/indicator/ NY.GDP.MKTP.KD.ZG?locations=ID

20 Kristina SA, Endarti D, Wiedyaningsih C, et al. Health care cost of noncommunicable diseases related to smoking in Indonesia, 2015. Asia Pac J Public Health 2018;30:29-35.

21 Bundhamcharoen K, Aungkulanon S, Makka N, et al. Economic burden from smoking-related diseases in Thailand. Tob Control 2016;25:532-7.

22 Ekpu VU, Brown AK. The economic impact of smoking and of reducing smoking prevalence: review of evidence. Tob Use Insights 2015;8:TUI.S15628-35.
23 Cahill K, Stevens S, Perera R, et al. Pharmacological interventions for smoking cessation: an overview and network meta-analysis. Cochrane Database Syst Rev 2013;5:Cd009329.

24 Trapero-Bertran M, Leidl R, Muñoz C, et al. Estimates of costs for modelling return on investment from smoking cessation interventions. Addiction 2018;113 Suppl 1:32-41.

25 Bartecchi CE, MacKenzie TD, Schrier RW. The human costs of tobacco use (1). N Engl J Med 1994;330:907-12

26 Jha P, Chaloupka FJ. The economics of global tobacco control. BMJ 2000;321:358-61.

27 Cleghorn CL, Blakely T, Kvizhinadze G, et al. Impact of increasing tobacco taxes on working-age adults: short-term health gain, health equity and cost savings. Tob Control 2018;27:e167-70.

28 World Health Organisation. WHO report on the global tobacco epidemic, 2019. Country profile: Indonesia [Internet], 2019. Available: https://www.who.int/tobacco/surveillance/policy/country_profile/idn. pdf

29 World Health Organisation. Tobacco free initiative (TFI): Taxation [Internet]. Cited Sep 26, 2019. Available: https://www.who.int/ tobacco/economics/taxation/en/

30 Bolin K. Economic evaluation of smoking-cessation therapies: a critical and systematic review of simulation models. Pharmacoeconomics 2012;30:551-64.

31 Ruger JP, Lazar CM. Economic evaluation of pharmaco- and behavioral therapies for smoking cessation: a critical and systematic review of empirical research. Annu Rev Public Health 2012;33:279-305.

32 Gordon L, Graves N, Hawkes A, et al. A review of the costeffectiveness of face-to-face behavioural interventions for smoking, physical activity, diet and alcohol. Chronic IIIn 2007;3:101-29.

33 Annemans L, Nackaerts K, Bartsch P, et al Cost effectiveness of varenicline in Belgium, compared with bupropion, nicotine replacement therapy, brief counselling and unaided smoking cessation: a BENESCO Markov cost-effectiveness analysis. Clin Drug Investig 2009;29:655-65.

34 Hurley SF, Matthews JP. The quit benefits model: a Markov model for assessing the health benefits and health care cost savings of quitting smoking. Cost Eff Resour Alloc 2007;5:2. 